\title{
EL VÉRTIGO DE LAS IDENTIDADES: SECRETOS Y PERSONALIDADES FALSAS EN EL CINE DE HITCHCOCK
}

\section{Identities in the whirlwind: secrets and fake personalities in Hitchcock's \\ cinema}

\author{
Pablo Francescutti* \\ * Universidad Rey Juan Carlos \\ luispablo.francescutti@urjc.es
}

Palabras clave

Secreto

Identidad

Alfred Hitchcock

Cine

Simmel

\section{Resumen}

En las películas de Alfred Hitchcock, secreto e identidad personal se entrelazan de manera eminente. En sus elencos abundan personajes acusados de delitos que no cometieron, individuos con un pasado oculto, sujetos confundidos con otros, chantajistas que buscan lucrarse con secretos ajenos, agentes dobles, impostores y personalidades escindidas. En sus tramas nadie es lo que parece, todos esconden algo. La identidad es la suma de las máscaras, tal es su mensaje central: también somos lo que ocultamos. Aplicando el corpus teórico desarrollado por Georg Simmel, Erving Goffman, Umberto Eco y otros autores, en este artículo se intenta demostrar desde una perspectiva novedosa que la filmografía del director británico es una concienzuda puesta en escena de las interacciones creadas por la retención deliberada de información, tanto en lo público (secretos oficiales) como en lo privado (secretos personales y familiares). Tales interacciones, revela el análisis, se hallan atravesadas por un hilo rojo: la naturaleza maleable de las identidades. Al escenificar sus ambigüedades y paradojas, estos filmes rinden un valioso servicio a la mirada sociológica interesada en fenómenos en proceso de definición, como identidades falsas, robo de identidades y relaciones entre identidades online y offline.

\section{Abstract}

The intertwining of secret and personal identity features prominently in Alfred Hitchcock's cinema. Its plots are full of people falsely accused, mistaken identities, characters with a hidden past, double agents, blackmailers, impostors, split personalities, etc. In these movies nobody is what it seems, everybody has something to hide. Identity is the sum of all the masks, such seems to be one of the messages: we also are what we conceal. Building on the theoretical frame developed by Georg Simmel, Erving Goffman, Umberto Eco and others scholars, we intend to show from a novel approach that Hitchcok's filmography can be seen as a thorough investigation of the many interactions stimulated by secrecy, both in the public (secret of State) and private level (personal secrets, family secrets). Additionally, our analysis brings into light one of the main leitmotiv underlying those interactions: the malleability of identity, the source of its destabilization. The enactment of its ambiguities and paradoxes provides useful guidance to the sociologist for interpreting phenomena in the making, as fake identities, identity thefts and the relationships between offline and online identities.

Francescutti, P. (2016). El vértigo de las identidades: secretos y personalidades falsas en el cine de Hitchcock, Papeles del CEIC, vol. 2016/2, papel 162, CEIC (Centro de Estudios sobre la Identidad Colectiva), Universidad del País Vasco, http://dx.doi.org/10.1387/pceic.16176 


\section{INTRODUCCIÓN}

La obra de Alfred Hitchcock, de rango canónico en el panteón cinematográfico - su largometraje Vértigo ha sido declarado la mejor película de la historia del cine- ha sido estudiada con los más variados enfoques, desde la Queer Theory al feminismo, aparte del psicoanálisis, la crítica, los Film Studies o incluso una óptica sociológica al servicio del análisis parsoniano de la familia (Deflem, 2007). En este artículo la abordaremos desde una perspectiva novedosa, con eje en la categoría de secreto y una constelación de conceptos anexos como privacidad, transparencia, opacidad. Nuestra mirada se inscribe en el linaje inaugurado por Georg Simmel con su seminal texto El secreto y las sociedades secretas (1906) y enriquecido por autores enrolados en la sociología, la semiótica, la antropología y la mediología.

Muy diversas son las relaciones e interacciones sociales a las que da lugar la información intencionalmente retenida; en este texto privilegiaremos las tocantes a la identidad personal. La elección no es arbitraria; la literatura especializada ha subrayado la centralidad de la problemática de la identidad en el cineasta británico. Este tema ha motivado indagaciones de corte psicológico, pero en ningún caso se le ha analizado a la luz de su conexión con el secreto entendido como forma social. Tal es el objetivo de este trabajo que no pretende ser una investigación de las identidades en Hitchcock, para lo cual haría falta otro cuerpo teórico, sino una exploración del fenómeno del secreto a través de las identidades escenificadas en su filmografía, y en esos términos el lector debe juzgarlo'.

\section{TEORÍAS DEL SECRETO}

Le cabe a Simmel el mérito de haber hecho del secreto un objeto sociológico legítimo. Decía Robert Nisbet (1990: 139) que "lo que hace Durkheim con el suicidio lo hace Simmel -aunque de una manera diferente, pero vinculada a aquella - con el secreto: lo extrae del reducto del individuo que lo 'guarda' y lo coloca directamente entre las relaciones y procesos de la sociedad".

\footnotetext{
${ }^{1}$ Este trabajo recoge parte de las conclusiones elaboradas en el marco del proyecto de I+D "El periodista como historiador del presente: análisis del documento en las nuevas formas de la información" (Ref: CSO2014-55527-P).
} 
Que Simmel escogiera tan peculiar tema tenía mucho que ver con su contexto: el tránsito de la comunidad tradicional a la sociedad de masas, de la indiscreta vida pueblerina al anonimato de las urbes donde se trata con gente que apenas se conoce. Del secreto, forma social, no le interesaban sus contenidos variables sino sus consecuencias: posiciones de poder, estados de conocimiento, relaciones de alianza y posibilidades de traición. Tomando de pieza de demostración la sociedad secreta, advirtió que la posesión de un secreto banal es lo que separa a los iniciados de los de fuera. Observó además que el secreto abre enormes resquicios a la identidad personal, pues "ofrece la posibilidad de que surja un segundo mundo, junto al mundo manifiesto, y que este último sufra con fuerza la influencia del primero" (1906: 462). En efecto, en la medida en que la identidad depende de relaciones de inclusión/exclusión, el secreto cumple un papel de primer orden en su formación y mantenimiento. En la tribu primitiva, el ingreso a la madurez viril lo determina la socialización de secretos de los cuales se excluyen a las mujeres y los niños. Y en la sociedad moderna, carente de ritos semejantes, la reserva del adolescente ante sus padres se torna un requisito sine qua non para la formación de su privacidad y, por ende, de su personalidad (Finkenauer, Engels y Meeus, 2002). Podrían llenarse páginas y páginas con ejemplos de la función cohesiva y sin embargo individualizante de la retención deliberada de información; función que llevó a Simmel a afirmar, a contrapelo de la tradición iluminista que lo execraba, que el secreto es "una de las grandes conquistas de la Humanidad" (1906: 462).

Erving Goffman ahondaría en el nexo entre secreto e identidad. Si en La presentación de la persona en la vida cotidiana (1959) examina la capacidad del actor social para manejar los secretos ligados a sus múltiples roles, en Estigma (1963) se ocupa de la seguridad buscada con una presentación irreprochable del propio pasado mediante el disimulo de "lagunas biográficas" sobre hechos inconfesables. Al sociólogo de las situaciones le intriga el malestar identitario de los sujetos con antecedentes estigmatizados (enfermedades vergonzantes, tendencias sexuales non sancta, historial penal, etc.), condenados a invertir ingente energía psíquica en gestionar la información relativa a sus "fallos" para exhibir una apariencia normal. Abocadas a evaluar en todo momento "si mostrar o no, si contar o no, si mentir o no, si revelar o no, y en cada caso, a quién, cómo, cuándo y dónde" (1963: 42), tales personas se 
obligan a mantener una disposición hípervigilante capaz de sumirles en la eterna duda de si su secreto está realmente oculto o corren el riesgo de sufrir chantaje o escarnio público.

La dimensión discursiva del secreto no pasó desapercibida a los semiólogos, para quienes es algo inherente a la comunicación. Louis Marin ha descrito su lógica con una fórmula (2012): A sabe de B algo que éste ignora de sí mismo, algo que debería o le convendría saber; luego $A$ comparte ese saber con C. "El secreto adquirirá todo su poder en el momento en que $B$ empiece a seguir las señales y las marcas que le identifican como su destinatario" (Ibid.: 21). Paolo Fabbri destaca su inestabilidad (1990): lo que hoy es secreto, mañana no lo será. La dialéctica ocultación/revelación provoca el incesante corrimiento del secreto. "Representarse el secreto en movimiento significa romper con la imagen tenebrosa del esqueleto puesto en el armario y convertirlo más bien en un 'secreto de Polichinela', un secreto irrisorio, desvirtuado por su desplazamiento" (Ibid.). En cualquier caso, produce efectos de sentido. "La fuerza de un secreto está en ser siempre anunciado pero nunca enunciado. Si se enunciara perdería su fascinación. El poder de quien anuncia un secreto es poseer un secreto vacío", advierte Umberto Eco (1992: 98). De alli la ingenua y difundida presunción de que el "conocimiento secreto" es veraz "porque solo lo que se halla debajo de la superficie puede permanecer oculto largo tiempo. De ese modo la verdad se identifica con lo no dicho o con lo que he dicho de forma oscura" (Ibid.: 30). A menudo, el secreto se asocia a la capacidad de ostentar más de una identidad; de ahi el valor heuristico que tiene la figura del agente doble, traidor al cuadrado y fenomenólogo de las apariencias normales y las ocultas. "Todos somos agentes dobles en los microescenarios de la vida cotidiana", afirma Fabbri (2012: 127). Y, asumiendo que la circulación de la comunicación se halla sujeta a las reglas del secreto, proclama que su estudio se enriquecerá si se la observa a través de las lentes de espías y agentes dobles.

El atractivo del agente doble dimana de la obsesión del psiquismo contemporáneo con el fantasma del desdoblamiento de la personalidad, explica Alain Dewerpe (1994). El sentimiento ambiguo de seducción y rechazo que inspiran los personajes dúplices nace de nuestro deseo de saber de los demás y del temor a ser conocidos, del miedo a la falta de concordancia entre la identidad social y la personal. Accionando esos resortes afectivos, los ladrones de secretos nos perturban a la vez que 
nos fascinan. "El espía no es por tanto escogido al azar: sus rasgos movilizan las figuras culturalmente determinadas de lo familiar, de lo insospechable. De ellas será de quienes se sospechará en primer lugar, porque es claro que lo más cercano es lo más peligroso (Ibid.: 385). No es casual que en las ficciones se descubra que el amigo fiel, la esposa, el marido o el padre no son lo que aparentan.

La economía psíquica descrita no se entiende al margen del estatuto del secreto como piedra basal del individualismo. Un resultado crucial de las Guerras de Religión fue que el Estado absolutista le concedió a la conciencia - el campo de batalla de católicos y protestantes- un fuero inexpugnable a la intromisión de los poderes públicos (Koselleck, 2007). Ese fuero interno será el baluarte de la privacidad del individuo. A partir del siglo $X X$, ese bastión de la subjetividad moderna - constituido por un cúmulo de secretos íntimos cuya destrucción acarrearía la de la personalidad- se verá asediado por las dudas acerca de la unidad del Yo. El hallazgo psicoanalítico de la escisión entre la personalidad visible y una profundidad negada y escondida acrecentará el temor a no ser lo que creemos. "Portadora de una crisis de identidad ligada al crecimiento de la intimidad y a la hegemonía generalizada del individualismo en la configuración original de la modernidad occidental, esa mirada permanente a nosotros mismos, esa división entre la parte que mira y la parte mirada, trae consigo la sospecha de disociación" (Dewerpe, 1994:387). De tales sospechas se derivaría la fuerte inversión imaginaria y afectiva del público en la fruición de narraciones de criminales y espías.

Puede decirse que a cada formación social le corresponde un régimen del secreto. La Edad Moderna, guiada por el realismo político, abrazó la doctrina de los arcana imperii ${ }^{2}$ : el entendimiento del secreto como técnica auxiliar de la cual ningún gobernante puede prescindir (Horn, 2011). A partir de la llustración, el secretismo como principio de gobierno fue cuestionado y posteriormente arrinconado por el ideal de la publicidad, que moraliza el secreto y lo tacha de patología política. Sin embargo, observa Horn, el cortocircuito entre el anhelo de transparencia y la persistente opacidad del Estado democrático pone en

\footnotetext{
${ }^{2}$ Literalmente "secretos del poder" en latín, en referencia a los misterios insondables del poder encarnada en la figura del monarca. Esbozados en el imperio romano, los arcana imperii toman forma doctrinaria en el realismo político de Maquiavelo, dando pie a la gestación de la idea de "Razón de Estado" (Donaldson, 1988).
} 
aprietos al pensamiento liberal, incapaz de dar cuenta de la vigencia de los desprestigiados arcana imperii. La discrepancia alimenta el recelo colectivo en la realidad garantizada por el Estado-Nación y sus expertos; se barrunta que es ilusoria y oculta un mundo caótico e inquietante. Calmar esa ansiedad es la razón de ser de los relatos detectivescos y de espionaje, observa Luc Boltanski (2012), quien encuentra muy significativo el hecho de que esos géneros suspicaces y la categoría clínica de paranoia cristalizacen simultáneamente a lo largo del siglo XIX.

La caracterización del régimen del secreto en la sociedad de la información quedaría incompleta sin una mención al rol de los mass media. Al respecto resultan de gran utilidad las observaciones de Joshua Meyrowitz (1985) acerca de la erosión de la privacidad bajo el embate de las tecnologías de la comunicación masiva. Siguiendo la senda abierta por la "máquina reveladora de secretos", la televisión, e invocando como ella el derecho del público a saber, los medios electrónicos alzan el velo existente entre hombres y mujeres, entre adultez e infancia, entre gobernantes y gobernados y con ese movimiento borran la frontera entre el backstage y el frontstage de la dramaturgia social. Sin proponérselo, promueven una remodelación de las identidades individuales, que varían en función del acceso a la información; vale decir, de la situación de cada individuo de cara al sistema de medios. En los viejos tiempos, "la conciencia de la identidad se basaba en experiencias compartidas dentro de un grupo e inaccesibles a quienes no formaban parte de él", recuerda Meyrowitz (2013: 170). Ahora, la mayor transparencia social diluye las lindes de las identidades de género, con la consecuencia de que las mujeres adoptan rasgos tradicionalmente masculinos y viceversa, y otro tanto hacen con las barreras etarias (los adultos no reprimen sus comportamientos "infantiles", los niños se expresan y actúan con maneras antes impensables). En suma, se produce una homogeneización de las identidades y de las conductas asociadas.

Al panorama delineado por Meyrowitz cabe añadir que, precisamente en virtud de las mutaciones fomentadas por el sistema mediático, hoy "existe más control sobre la información, y más información para controlar, y más espacio para ocultar la información a los demás. Las reglas sobre revelación y ocultamiento también están más desarrolladas" (Marx y Muschert, 2008: 218). ¿Hasta qué punto las 
transformaciones han repercutido total o parcialmente en las dinámicas del secretismo identificadas por Simmel? A falta de estudios comprensivos que despejen la incógnita, las investigaciones del impacto de las fugas de información clasificada promovidas por el portal de filtraciones Wikileaks (Francescutti et al., 2012; Lozano, 2014; Serra, 2014) dejan entrever que dichas dinámicas siguen vigentes y han ganado en complejidad gracias a la aparición de nuevos actores (piratas informáticos, whistleblowers...) y prácticas discursivas como la retórica de la transparencia y el espectáculo de la revelación ${ }^{3}$ contra un fondo de proliferación de falsas identidades online por cuenta de simples usuarios o de ciberactivistas como los Anonymous (Wiszniewski y Coyne, 2002).

\section{HITCHCOCK Y EL SUSPENSO}

¿Qué se sabe de la actitud de Hitchcock frente al secreto? Como advertíamos al principio, la bibliografía inspirada en el cineasta - tan voluminosa que puede hablarse de una disciplina aparte, los "Hitchcock Studies" - no ha profundizado en ese punto, pero si ha indagado en torno a dos elementos capitales de su poética muy relacionados con aquel: el suspenso y el McGuffin.

Aunque Hitchcock no inventó el suspenso - los antecedentes de este recurso dramático se remontan a Aristóteles y, más recientemente, a la radiofonía estadounidense de los años 30, que lo introdujo para mantener al oyente enganchado a sus programas-, a él le corresponde el crédito de haberlo popularizado. A esta "estrategia para acumular, liberar y regular la implicación afectiva dentro y a través de una vasta gama de formas mediáticas" (Krutnik, 2013:6), el cineasta la resumió del siguiente modo: "dar al público una información que los personajes de la historia no conocen todavía; gracias a este principio el público sabe más que los protagonistas y puede plantearse con más intensidad la pregunta: ¿cómo podrá resolver la situación?" (cit. en Truffaut, 1974: 95).

\footnotetext{
${ }^{3}$ Por retórica de la transparencia entendemos los recursos persuasivos aplicados a la construcción de un ethos personal o institucional de sinceridad y ausencia de secretos; el espectáculo de la revelación, por su parte, denomina a las puestas en escena de primicias mediáticas cuyo contenido es la exposición de información confidencial. Ejemplo palmario de auto-referencialidad periodística, el verdadero objeto de tales escenificaciones no es el secreto revelado sino la ideología de la prensa como Cuarto Poder. Ninguna de estas prácticas sería concebible fuera de sociedades ultramediatizadas con un régimen tan restrictivo del secreto como las nuestras. Véanse Alonso (2014) y Francescutti (2014).
} 
Se deduce de la definición que el suspenso se construye a partir de la distribución de información esencial para el avance de la trama; requiere, además, que el desenlace sea incierto; de lo contrario solo habría fatalismo. No tiene por objeto únicamente hechos violentos o peligrosos; se activa igual cuando una telefonista escucha furtivamente la conversación de dos enamorados y anhela saber si el pedido de casamiento formulado por el hombre acabará en boda o no (Ibid.: 74); aunque Hitchcock acumula tensión valiéndose de la expectativa de un acontecimiento violento (no es gratuito que sus películas fueron etiquetadas "thrillers", término traducible por "escalofriante", o "que produce escalofríos").

El otro recurso estratégico es el McGuffin. Pretexto o disparador de la acción, "el McGuffin es, por tanto, el nombre que se da a esta clase de acciones: robar los papeles, robar los documentos. Los "papeles o los "documentos" o los "secretos" de construcción de la fortaleza deben ser de una gran importancia para los personajes de la película, pero nada importantes para mí, el narrador" (Truffaut, 1974: 115). El McGuffin puede ser el halo misterioso que envuelve a una persona, dinero robado, joyas, un cadáver que aparece inopinadamente, o un secreto de Estado; y en todas las ocasiones sirve de "gancho" para manipular la atención del espectador, despertando su deseo de saber mientras se despliega la trama. Y al decir de Hitchcock, la fórmula era eficaz: "Comparte tus secretos con la audiencia y ésta pagará intereses por ellos" (cit. en Gotlieb, 1997: 264).

Recapitulando: el suspenso se sostiene sobre una información relativa a los personajes en pantalla - a menudo de carácter confidencial-que se comparte con el espectador. El McGuffin, con su contenido anecdótico, su vacuidad radical, evoca de inmediato la concepción formalizada que Simmel tenía del secreto: éste no interesa más que por las relaciones que pueda generar o por las reacciones susceptible de desencadenar (1906). El contenido del McGuffin puede ser significativo para algunos personajes secundarios de la película, pero no para los protagonistas y menos para el director.

Valiéndose del suspenso y los McGuffins, Hitchcock confeccionó las "narrativas tensionales" de una cincuentena larga de películas. Aparte de ganarle la admiración de la crítica, ambas estratagemas le encumbraron en una industria cultural consagrada a suministrar a las masas secretos y revelaciones. A nosotros ellas nos servirán de pistas 
para reconstruir la concepción del secreto subyacente a unas formas simbólicas que pivotan en el conflicto entre la realidad superficial y la oculta.

\section{OBJETIVOS Y PROCEDIMIENTO}

Con este trabajo buscamos comprender el funcionamiento del secreto en la obra de Hitchcock. Nos proponemos identificar las interacciones a las que da lugar, en especial las relativas a las identidades de los personajes. En el plano narrativo procuraremos verificar si la función diegética del secreto se ajusta al modelo bosquejado por Marin. Por último, trataremos de inferir, a partir del análisis, la postura del cineasta frente al secreto, vale decir si adhiere a la doctrina de los arcana imperii, si defiende la transparencia o si se limita a defender la esfera privada. Con los resultados obtenidos trataremos de establecer el valor de esta filmografía de cara al abordaje sociológico del secreto.

Con esos objetivos en mente analizaremos los 56 largometrajes dirigidos por Hitchcock a lo largo de su trayectoria (las películas se identificarán con el título de su estreno en España, seguido del original en inglés).

Nuestra metodología será sencilla: en un primer paso verificaremos en cada argumento si alguno de los protagonistas encierra secretos acerca de su personalidad o de sus intenciones. Las obras que satisfagan ese requisito serán clasificadas de acuerdo a la siguiente tipología de secretos:

- secreto de Estado (información clasificada que los gobiernos juzgan de interés vital para la nación, incluido los secretos diplomáticos.)

- secreto profesional (la obligación legal que tienen ciertas profesiones de mantener en reserva la información suministrada por sus clientes, como el secreto médico, bancario y de las fuentes periodísticas)

- secreto judicial (datos personales e investigaciones incluidos en el sumario de una instrucción judicial y que no deben divulgarse durante un periodo acotado)

- secreto industrial (cualquier conocimiento técnico que por su valor competitivo el dueño de una industria quiera mantener oculto, por ejemplo, fórmulas o procesos de fabricación) 
- secreto de confesión (conocido en el derecho canónico como sigilo sacramental, es la obligación sacerdotal de no revelar jamás lo sabido por confesión sacramental)

- secreto personal (datos y conocimientos relativos a una persona que sólo esta conoce)

- secreto familiar (datos y conocimientos relativos a una familia o a uno de sus miembros que puedan perjudicar su imagen pública y que únicamente esta conoce; aquí incluimos también a los secretos de pareja y de "alcoba" - referidos a la intimidad sexual de la pareja-).

Formados los agrupamientos, identificaremos en cada caso las principales interacciones que el secreto promueve entre los personajes y la audiencia (por ejemplo, de alianza, de exclusión, etc.), con énfasis en las concernientes a las identidades. También prestaremos atención a las tipologías de personajes implicados en la gestión/revelación de la información oculta, y a la manera en que los desenlaces resuelven las expectativas creadas en torno a secretos e identidades. Finalmente, los datos elaborados por el análisis serán discutidos a la luz de las categorías expuestas en el apartado teórico.

\section{ANÁLISIS FÍLMICO}

\subsection{Clasificación}

Un rápido repaso de la filmografía de Hitchcock nos apercibe de que, exceptuando sus producciones del periodo 1922/1933, sus protagonistas siempre ocultan alguna clase de secreto ${ }^{4}$. En el corpus escogido hemos identificado cuatro clases de secretos: de Estado; personal; de familia; y de confesión, agrupamientos que pueden subsumirse en dos: secretos públicos y secretos privados. No hemos encontrado en él trazas de secretos industriales, judiciales o profesionales.

\footnotetext{
${ }^{4}$ En el período posterior a su etapa británica encontramos dos obras que no guardan relación con el secreto: Náufragos/Lifeboat, sobre las tribulaciones de los náufragos de un barco torpedeado por un submarino alemán; y Los Pájaros/The Birds, en la cual solo hay misterio (la conducta anómala de las aves): un asunto inexplicable del cual nadie tiene la solución (o, como reza la antigua acepción de misterio: "secretos solo conocidos por Dios").
} 


\subsubsection{Secretos de Estado}

En este apartado - el más poblado del corpus- se agrupan las tramas sobre secretos de índole política. Sus contenidos varían: el diseño del motor de aviación (Los 39 escalones/The 39 steps); cierta cláusula de un pacto internacional (Corresponsal extranjero/Foreign Correspondent); una ecuación anti-misiles (Cortina Rasgada/Torn Curtain); el secreto codificado en una tonada (La dama desaparece/The Lady vanishes); un plan magnicida (las dos versiones de El hombre que sabia demasiado/The Man who knew too much); microfilms escondidos en una estatuilla (Con la muerte en los talones/North by Northwest). De tenor parecido son las amenazas a la seguridad estatal planteadas por el sabotaje a una fábrica de aviones (Sabotaje/Saboteur), el programa atómico nazi (Encadenados/Notorious), la identidad desconocida de un espía alemán (Agente secreto/Secret Agent) o del "topo" del KGB infiltrado en la inteligencia francesa (Topaz).

El desarrollo argumental evidencia que tales contenidos son irrelevantes; lo que importa son las acciones que ponen en marcha. Lo dejó establecido Hitchcock al declarar que el McGuffin más vacío de toda su obra lo representaban los "documentos del gobierno" mentados en Con la muerte en los talones: que no se dé una pista de su contenido no afecta en lo más mínimo al curso de la trama. Igual ocurre en otros filmes: lo crucial es que Thornhill limpie su nombre, que Alicia Huberman traicione a su marido y escape con el agente secreto; que Barry Kane demuestre que no es el saboteador, etcétera.

Los espías son una minoría en el elenco, o desempeñan papeles secundarios. Con los secretos de Estado lidian periodistas (profesionales de la revelación) y sobre todo héroes accidentales: un operario, un publicitario, un médico, un novelista... Este dato marca una diferencia con las narraciones de espías convencionales, cuya acción la acaparan los espías y miembros de la administración.

\subsubsection{Secreto personal}

Los argumentos agrupados en este apartado, el segundo en importancia numérica, tratan de hechos comprometedores que afectan únicamente a un individuo. En Recuerda/Spellbound, conciernen a Ballantyne, que ha suplantado al Dr. Edwards, a quien cree haber asesinado; en Marnie la ladrona/Marnie, a Marnie, por el asesinato del hombre que la quiso violar; en Frenesi/Frenzy, al psicópata amigo de Richard; en Bajo el signo 
de Capricornio/Under Capricorn, a Henrietta, la asesina de su hermano; en Ventana Indiscreta/Rear Window, al asesinato cometido por Thorwald; en Vértigo, a la implicación de Judy en el "suicidio" de la mujer de Elster; en Psicosis/Psycho, a la relación de Norman Bates con su madre; en ¿Quién mató a Harry?/The Trouble with Harry, a la autoría del fallecimiento de Harry. Hechos relacionados con muertes, exceptuando la sexualidad desviada del protagonista de Psicosis y las dudas infundadas en La Sospecha/Suspicion: el marido de Lina no es el asesino en ciernes que ella intuía, sino un calavera a quien había malinterpretado. y en todas los casos se corresponden con los hechos biográficos estigmatizantes mentados por Goffman (1963).

Los protagonizan personas corrientes: psiquiatras, un reportero, un hotelero, una secretaria, un cazador, un magnate y su mujer... La policía y la justicia acuden al final para levantar acta del esclarecimiento de secretos de naturaleza delictiva, en el cual han tenido escasa intervención.

\subsubsection{Secretos de familia y de pareja}

En Rebecca, la información oculta se refiere al adulterio de Rebeca y a su muerte accidental; en La sombra de una duda/The Shadow of a Doubt, a los crímenes del tío de Charlie; en La Trama/Family Plot, a los secuestros extorsivos perpetrados por Arthur Adamson y su compañera; en Pánico en la escena/Stage Fright, al asesinato del marido de Charlotte cometido por Jonathan a instancias de aquella; en Marnie la ladrona, a la cleptomanía de Marnie y al historial de prostitución de su madre; y en La Soga, al asesinato perpetrado por dos universitarios. En este agrupamiento también prevalecen los secretos relativos a muertes, salvo dos casos de secretos de alcoba.

Los partícipes de los secretos son parejas heterosexuales (más el añadido ocasional de un amante), salvo el dúo asesino de La Soga, cuyo vínculo homosexual está sobreentendido.

\subsubsection{Secretos de confesión}

El único ejemplo lo tenemos en Yo confieso/I confess. En este filme se relata cómo un cura se entera en el confesionario del asesinato cometido por su sacristán. El hecho de que el difunto extorsionase en el pasado al religioso por un asunto de faldas, le convierte en sospechoso a ojos de la policía. De tal modo se ve ante la disyuntiva de probar su 
inocencia violando su deber o callar y acabar en la cárcel. Providencialmente, la infidencia de la mujer del sacristán le salvará.

\subsection{Interacciones sociales}

Las situaciones suscitadas por los secretos dan lugar a diversas interacciones, a saber:

\subsubsection{Chantajes}

La persona que esconde secretos comprometedores se expone a ser extorsionada. Así, en Chantaje/Blackmail, Alice es chantajeada por alguien que sabe que mató al pintor que quiso violarla; en Yo confieso, el abogado chantajea al cura a raíz de su antigua relación con una novia; en Crimen perfecto/Dial for Murder, el marido coacciona a un delincuente para que lo libre de su esposa; en Rebecca, el primo de Rebeca extorsiona al esposo homicida; en Pánico en la escena/Stage Fright, Eve es chantajeada por su criada a raíz del homicidio de su cónyuge; en Extraños en el tren/Strangers on a train, Bruno amenaza a Guy con implicarlo en el asesinato de su mujer si no cumple lo pactado; en Marnie la ladrona, el jefe de Marnie la obliga a casarse con él o la denunciará por robo. La extorsión ilustra el poder sobre las personas que otorga la posesión de secretos ajenos. Anotemos que, a excepción de Rebecca y Marnie la ladrona, los chantajistas acaban recibiendo su merecido.

\subsubsection{Inculpación errónea}

Héroe prototípico de Hitchcock, el falso culpable es alguien que, por el azar de las circunstancias, es tomado por otro y perseguido injustamente. Las causas de la confusión varían: un inocente se entera por casualidad de un secreto de Estado (el complot para robar planos militares en Los 39 escalones; una conjura magnicida en El hombre que sabía demasiado); o le imputan un delito que no ha cometido (el sabotaje en Sabotaje; un atraco en Falso Culpable/The Wrong Man; un crimen en Crimen perfecto; un robo de joyas en Atrapar al ladrón/To catch a Thief, el asesinato de un diplomático en Con la muerte en los talones; la muerte de la exmujer en Frenesí). El equívoco obliga al acusado a luchar por demostrar su inocencia, iniciando una huida que le arrojará de cabeza al submundo del crimen o del espionaje, hasta su 
confrontación final con el verdadero delincuente, un falsario camuflado de miembro de la clase alta ${ }^{5}$.

\subsubsection{Duplicidades}

Sinónimo de hipocresía y falsedad, la duplicidad califica una conducta simuladora. En la medida en que ella oculta la verdadera personalidad de alguien conecta con el secreto. Por lo general, el individuo dúplice posee una cara visible positiva y otra oculta y reprobable - el caso de los delincuentes-; pero a Hitchcock le gusta invertir los términos: en Encadenados, Alicia finge ser la fiel esposa de un conspirador nazi mientras colabora con el antifascismo. Otro tanto ocurre con los agentes dobles: la Eve de Con la muerte en los talones en apariencias trabaja para los soviéticos, pero en realidad es la agente del FBI buscada por estos; la Annabella Smith de Los 39 escalones traiciona a sus jefes alemanes en beneficio de los británicos; y el físico americano de Cortina Rasgada finge desertar a Alemania Oriental pero su verdadero objetivo es sustraer a su Estado comunista una ecuación científica estratégica. En ocasiones, la faceta "oficial" es simplemente anodina, como el "disfraz" de ayudante de camerino que adopta Eve en Pánico en la escena para aclarar un asesinato.

La duplicidad se materializa en el doble. El tema del doppelgänger, habitual en la literatura del siglo XIX (William Wilson, de E. A. Poe, es un ejemplo paradigmático), sugiere un fondo oscuro de nuestra persona al que los dobles encarnan, obligándonos a confrontarlo. A Hitchcock le sirve para escenificar los dualismos que desgarran el alma humana: el doble asesinato pactado en Extraños en el tren; la personalidad escindida de Norman Bates (Psicosis); la disociación del objeto amoroso de Scotty en Madeleine y Judy (Vértigo); el sacristán asesino, el otro Yo del sacerdote de Yo confieso; o la pareja de prósperos secuestradores respecto del dúo de timadores de poca monta en La Trama.

\footnotetext{
${ }^{5}$ Vestir como un burgués, residir en barrios elegantes, viajar en primera clase, en breve, camuflarse entre las clases altas es habitual en los espías de la vida real. La táctica de ocultación responde a un conocimiento intuitivo de las identidades sociales. "En ninguna parte es más cierta la convicción de que la sospecha está socialmente motivada por la relación estrecha y también ella misma socialmente construida, que asigna la calidad de 'sospechosas' a las posiciones más dominadas y la de 'seguras' a las posiciones dominantes" (Dewerpe, 1994: 350).
} 


\subsubsection{Alianzas}

La índole transgresora del secreto en ocasiones ayuda a forjar alianzas, a las que el melodramatismo de Hollywood impone un cariz sentimental. En Recuerda, la recuperación de su identidad arroja a Ballantyne en los brazos de Contance; en La sombra de una duda, la sobrina del asesino se une al detective bajo el acuerdo de ocultar las fechorias del difunto tío; en Encadenados, la maquinación de Alice contra su esposo refuerza su romance con el agente del $\mathrm{FBl}$; y en Rebecca, marido y mujer se reconcilian tras conocer ella el pasado oculto de él. De la tónica romántica escapa el pacto criminal de Extraños en un tren, basado en la complicidad que ata a Guy al psicópata Bruno.

\subsubsection{Trasiego de identidades}

En el universo de Hitckcock es tan frecuente ser privado de la identidad propia como apropiarse de otras ajenas. Así, el exdelincuente Robie de Atrapar al ladrón debe fingir ser un millonario para atrapar al verdadero criminal; en Los 39 escalones, Hannay se hace pasar sucesivamente por lechero, mecánico, evangelista y agitador político. Con la muerte en los talones riza el rizo: Thornhill asume el nombre de Kaplan, un agente secreto imaginario, y deviene un "falso culpable inexistente". Nótese que en este caso la recuperación de la identidad no restaura la situación de partida, ya que Thornhill deja de ser un frívolo inconsistente para convertirse en adulto responsable.

\subsubsection{Voyerismo}

A los secretos ajenos se accede con frecuencia por medio de un acto de furtivismo visual. Ejemplos: en Psicosis, el plano inicial de la ventana que muestra a la pareja retozando, y el agujero en la pared por el cual Norman Bates espía a su huésped; al comienzo de La Soga, el zoom a la ventana de un edificio que descubre el crimen que tras ella se está perpetrando; o, de modo paradigmático, las escenas intimas visibles a Jefferies en cada ventana del bloque de viviendas de Ventana Indiscreta, genuinas representaciones del backstage de la vida doméstica: para el fotoreportero fisgón sus vecinos carecen de privacidad, ya que su teleobjetivo cancela la distinción entre lo público y lo privado, disfrutando de un lugar de privilegio que le habilita a descubrir el asesinato cometido por uno de ellos. 


\section{DisCUSIÓN}

El análisis ha dejado claro el valor estratégico de la identidad en las intrigas. Muchas de estas se resumen en pesadillas de identidades: los protagonistas no saben quién es realmente su cónyuge, su pariente, o ellos mismos. Cunde la sospecha de que nunca se conoce a nadie, ni siquiera a quien se ama o con quien se vive ${ }^{6}$. La confusión mantiene el suspenso a lo largo de las películas: la audiencia comparte la angustia del personaje que ignora el verdadero yo de sus contrapartes actanciales.

Numerosos argumentos tocan la pérdida y recuperación de la identidad. A la postre resulta mucho más valioso aclarar el enredo de identidad que recobrar los planos secretos, los microfilms escondidos o lo que mande el McGuffin de turno. Por lo general, las peripecias culminan en el restablecimiento de la situación inicial, y a veces el pasaje a una identidad más plena, lo que le imprime a la trama un carácter iniciático (Marimbert, 1959: 83). Trátese de ardides malignos o de camuflajes necesarios para limpiar la reputación o hacer justicia, la idea es la misma: la identidad no es un dato natural, congénito, inmutable, sino una suerte de prenda que nos ponemos o nos ponen, algo que se puede intercambiar, perder y recobrar, aunque lo último signifique que la máscara vuelve a su sitio.

Dado que una buena porción de las identidades en liza están ocultas o son falsas, el secreto comparece obligadamente. Fenómeno transversal, el secreto atraviesa todos los estamentos, los bajos fondos y las altas esferas (las clases respetables, digamos de pasada, no salen bien paradas: a ellas pertenece la mayoría de los villanos). Fomenta alianzas, propicia separaciones, motiva traiciones y concede poder sobre quienes ignoran su contenido (en Rebecca, el ama de llaves controla a la segunda esposa porque sabe algo ominoso acerca de la primera) y sobre quienes no quieren revelarlo (las víctimas del chantaje). Su influencia no se debilita siquiera cuando resulta ser un McGuffin vacío. Por añadidura, un

\footnotetext{
${ }^{6}$ La radicación de Hitchcock en Hollywood en los años 40 despierta su interés por la vulgata freudiana conspicua en la cultura de masas estadounidense. Su fascinación con las memorias reprimidas, los traumas de origen sexual, la personalidad escindida y el inconsciente que gobierna y oculta nuestra verdadera personalidad y por lo tanto adquiere el rango de secreto máximo, alimentan la visión pesimista de la condición humana que exudan sus filmes, potenciada por una interpretación conservadora del psicoanálisis. Ver: Sandis, 2009.
} 
secreto falso puede esconder uno verdadero (en Recuerda, la errónea atribución a Ballantyne del asesinato del Dr. Edwards tapa la muerte accidental de su hermano), o engendrar uno nuevo: el ocultamiento del cadáver de Harry por sus tres supuestos asesinos en ¿Quién mató a Harry?

Hemos visto que los secretos personales y los oficiales dominan las tramas. Los primeros dan lugar a un muestrario de posibles derivaciones de las situaciones descritas por Goffman, protagonizadas por individuos marcados por las cualidades "deshonrosas" señaladas por el microsociólogo: prostitución, trastornos psiquiátricos, criminalidad; un pasado que les torna presa fácil del chantaje.

Pasemos al secreto de Estado. En las películas, la "guerra secreta" de los espías es un asunto rutinario. Entra dentro de lo normal que los Estados atesoren secretos o intenten robárselos mutuamente, y que en esa pugna se cometan asesinatos. Notablemente, la mayoría de los escenarios se sitúa en el terreno del contraespionaje (acción defensiva) más que en el del espionaje (acción ofensiva). Ingleses, estadounidenses y franceses aparecen como víctimas de espías extranjeros, rara vez como victimarios. Obsérvese que el espionaje es presentado como una actividad individual. Hitchcock no registra su burocratización patente en el surgimiento de las mastodónticas agencias de inteligencia; diríase que se quedó fijado en la fase inicial del género, protagonizado por diletantes de las clases altas. Desde luego, algunas obras suyas toman distancia de la amoralidad de la guerra secreta, pero sin llegar a criticar el sacrificio de la legalidad en el altar de la razón de Estado, tal como lo hacen las novelas de John Le Carré. Hitchcock da reiteradas pruebas de su adhesión a los arcana imperii, mereciendo la etiqueta de "Cold War liberal" colgada a quienes durante la Guerra Fría combinaban la defensa de la democracia con un despiadado anticomunismo (Corber, 1993). Pero en el fondo los secretos oficiales le traen sin cuidado; si los pone en juego es con el solo propósito de agrietar la superficie de la rutina diaria de manera de que aflore el mundo soterrado. La normalidad aparente se revela entonces el camuflaje de una realidad siniestra, tal como el paisaje suizo, burgués y convencional como una postal, cede sitio al orden nazi en La dama desaparece (Bonitzer, 2002: 22).

Apuntaba Simmel (1906) que el momento crítico de la carrera del secreto es la revelación; en ella se libera la tensión contenida en su posesión. En las películas se manifiesta en dos formas: el 
desenmascaramiento (forzoso) y la confesión (voluntaria). A propósito de esta última comenta John Orr que "para Hitchcock, a quién se confiesa uno es tan importante o más que lo que se confiesa" (2005: 37); una observación que conecta con lo dicho por Simmel acerca de la superioridad de las interacciones sociales generadas por el secreto sobre sus contenidos eventuales (de hecho, la revelación de la propia identidad oculta suele propiciar alianzas con el destinatario de la confesión).

Llamativamente, las revelaciones se ventilan en privado. No abundan las exposiciones públicas. Los secretos oficiales permanecerán bajo siete candados. Unos malvados se llevarán sus secretos a la tumba y los de otros serán cubiertos con un piadoso silencio, a menudo sellado con el acta matrimonial del héroe y la heroína. Al optar por este tipo de clausura narrativa nuestro demiurgo se diferencia del cine de indagación periodística o judicial, escorado al espectáculo de la revelación. Al dar el protagonismo a las personas comunes se distingue igualmente de las ficciones de espías al uso, cuyos héroes se reclutan en los gestores legitimados del secreto de Estado: políticos, periodistas, jueces y agentes del Poder Ejecutivo. Por añadidura, el mediocre desempeño de los agentes de la ley en sus tramas le aleja del género policial (la proliferación de "falsos culpables" no habla precisamente a favor de su eficacia).

Hitchcock confesó que prefería personajes corrientes porque a la audiencia le costaba empatizar con detectives $u$ otros tipos humanos ajenos a su cotidianidad. Su empeño en inducir la identificación del público con los actantes nos conduce al punto central del análisis: de todas las interacciones habilitadas por el secreto en los filmes, la decisiva es la que se establece entre el autor y la audiencia. Sobre la premisa compartida de que todos ocultan algo, la estrategia del cineasta pasa por dar a ésta acceso a la privacidad de sus personajes. El conocimiento que éste adquiere de esa intimidad, sumada a sus sospechas acerca de las intenciones de los actantes y del autor, es fuente de una placentera mezcla de miedo y ansiedad. Su participación se consuma en el acto voyeurista. En Ventana Indiscreta, el teleobjetivo -metáfora de un poder mediático capaz de borrar las fronteras de lo público y lo privado- introduce al espectador en la trastienda del vecindario. Su intromisión en la intimidad de una pareja crea un peculiar menage à trois, con la cámara (i.e. la audiencia) ocupando el tercer 
vértice del triángulo. En otras películas, el voyeurismo motiva que el espectador se sorprenda deseando que no se descubra al criminal, la mejor prueba de cuánto ha logrado el cineasta implicarlo en el secreto.

Por esa vía, el cine de Hitchcock premia al espectador con una doble gratificación: vivir desde la seguridad de la butaca peripecias peligrosa coronadas por tranquilizadores happy endings: los malvados reciben su merecido (en particular los chantajistas, prototipo del violador de intimidades), los falsos culpables prueban su inocencia, los secretos de Estado se mantienen a buen recaudo y las identidades son recuperadas. El colofón lo pone la formación o consolidación de una pareja heterosexual ${ }^{7}$. En la medida en que el romance presupone un voto de confianza en el partenaire, los finales románticos mitigan los sentimientos de decepción y recelo infundidos por las deslealtades y sospechas que saturan las intrigas. y en ese sentido sus narraciones realizarian la misma contribución al apuntalamiento del orden social que Bolstanski atribuye a los géneros policiales y de espionaje.

\section{CONCLUSIONES: UNA EXPLORACIÓN MINUCIOSA DEL SECRETO PÚBLICO Y PRIVADO}

Hay elementos suficientes para interpretar el corpus analizado como una reafirmación de la relevancia del secreto en la vida moderna incluso en entornos de máxima intimidad-, así como una exploración minuciosa de sus facetas pública y privada. El gusto de Hitchcock por los McGuffins insignificantes pero cargados de consecuencias le aproxima a Simmel, para quien "el secreto era una forma idealizada que le interesaba más por lo que podía decirnos de la sociedad y de la conducta humana que por su contenido" (Marx y Muschert, 2008: 220). Y su afición por las situaciones vividas por sujetos sometidos a control recíproco le acerca a Goffman; en especial las creadas por secretos y confusiones identitarias ${ }^{8}$.

\footnotetext{
${ }^{7}$ El conocedor de Hitchcock invocará una excepción a la regla: Vértigo. En efecto, no hay en ella un final feliz. Su fascinación con los dobles traerá la desgracia de Scotty, la doble pérdida de su objeto amoroso.

${ }^{8}$ Sus argumentos consisten en derivaciones de una situación básica: un cura conoce en el confesionario al autor del crimen del que le acusan, viéndose en la disyuntiva de violar el secreto o condenarse; un espía convence a la mujer que ama de que finja amor a un nazi para desbaratar un complot; un inocente es confundido con un delincuente y debe huir para salvarse; dos criminales esconden un cadáver en el salón en el que ofrecerán un reunión social; y así.
} 
Adoptar esa temática obliga necesariamente a posicionarse frente al régimen del secreto. En el plano político, Hitchcock no deja dudas, siempre se muestra respetuoso con los arcana imperii: sus héroes velan por los secretos del propio Estado y por arrancar los suyos al enemigo. Lo patológico, a su modo de ver, no radica en la opacidad política sino en lo que se esconde en la esfera privada. ¿Le convierte esta convicción en un cruzado de la transparencia individual? Su postura no es univoca: ora defiende la lealtad del cura al sigilo sacramental contra el requerimiento policial, ora justifica el fisgoneo a los vecinos en aras de la justicia, mientras deja entrever que la sociedad de la vigilancia no se origina tanto en el aparato estatal como en el deseo irrefrenable del individuo de inmiscuirse en la interioridad del prójimo. Y cada tanto nos recuerda que determinados secretos deben permanecer ocultos por el bien de la pareja y la familia. De haber una ética implícita en su obra ambivalente se definiría por el respeto al secreto oficial (del Estado propio, claro está), el valor redentor de la confesión (herencia de su formación católica), la necesidad de simular cuando peligran bienes superiores y el deber de exponer las conductas criminales; eso sí: evitando siempre el espectáculo de la revelación; todo se dirime en el espacio compartido por los protagonistas, el cineasta y el espectador ${ }^{9}$.

Las interacciones motivadas por el secreto desembocan en un vértigo identitario. Las proteicas identidades se asumen con la misma facilidad con la que se las descartan, fungen de moneda de cambio. Los seudónimos se multiplican y ponen al descubierto las fracturas del sujeto ligadas al cambio de nombre (Goffman dixit). Dobles y falsos culpables llevan la mascarada al paroxismo. Priman la indiscernibilidad, la inestabilidad, la maleabilidad. Justos y réprobos se entregan a la simulación en un mundo apócrifo a la enésima potencia, donde todos actúan de agentes dobles.

Confusiones y enigmas no suponen ninguna novedad en la ficción occidental; la materia de la literatura decimonónica está hecha de secretos de familia (Lenoir-Bellec, 2004). La peculiaridad de Hitchcock

\footnotetext{
${ }^{9}$ Esa afirmación vale en contraposición al cine de indagación judicial del cual la obra de Elio Petri es paradigmática, o al de pesquisa periodística representado por All the president's men (A. Pakula, EE UU, 1976), The China Syndrome (J. Bridges, EE UU, 1979), o The Insider (M. Mann, EE UU, 1999). Hitchcock desdeña el clímax de la gran denuncia que escandaliza a la opinión pública y vindica al héroe; lo que no quita que él, al saciar la expectativas insufladas al público con el suspenso, fuese un miembro conspicuo de la industria abastecedora de secretos y revelaciones a las masas.
} 
estriba en el inestable Yo de sus criaturas. En Sue, Balzac o Zola, las personalidades que afloraban al término de los relatos eran de una sola pieza; aquí no hay certezas definitivas: tras la fachada quizás no haya nada, tal vez otra máscara. Una idea se abre paso: la identidad es la suma de todas nuestras máscaras: también somos lo que ocultamos. Hitchcock oscila entre la condena de los simuladores y el regodeo con los dualismos, ganándose con ello la acusación de ambigüedad moral.

Pero la gran originalidad del director pasa por la implicación de la audiencia en el secreto. Su esquema narrativo sigue a pie juntillas el modelo de Marin: el cineasta (A) le cuenta a $C$ (el público) algo que sabe de $B$ (el personaje) y que éste ignora. Esta lógica coloca a las obras estudiadas por fuera de las convenciones del cine policíaco y de pesquisa judicial/periodística, que estipulan que el espectador sea mantenido en la ignorancia de los secretos en liza y se vea obligado a acompañar al héroe en su lucha por destapar la verdad oculta. Dentro de ese marco, el mecanismo del suspenso -la vibrante expectativa instilada en la audiencia ante la revelación de un secreto que puede ser real o no- demuestra su funcionalidad: tema y técnica diegética se complementan a la perfección.

El recorrido cronológico del corpus enseña que Hithcock dedicó su carrera a perfeccionar su control de la posición de la audiencia como copartícipe del secreto, manipulando con ese propósito la pasión de la mirada y el miedo del voyeur a ser visto. Su búsqueda continua de personajes y situaciones que faciliten la identificación le condujo a detectar y explotar crisis y temores que, como señala Dewerpe, acosan a las identidades sociales y privadas de nuestros días. Y para ello supo aprovechar como pocos las limitaciones técnicas del cine, "forma que nos muestra la confrontación del exterior de los seres humanos y deja su interior a nuestra imaginación" (Thomson, 2010: 810), sobresaliendo en un arte que, al decir de Christian Metz, "se las ingenia para ser exhibicionista y hermético a la vez" (1977: 95).

La obra concebida de acuerdo a esos parámetros viene a confirmar la irreductible opacidad de lo social y de lo político. Hitchcock comparte con Canetti la intuición de que "el secreto se halla en la médula misma del poder" (Canetti, 1960: 342), sin desbarrar en teorias conspirativas. Desde luego, un observador habituado al contexto actual en donde la información sensible se gana y se pierde en las redes digitales, encontrará bastante obsoleta su visión del secreto de Estado y de la 
mecánica del espionaje. No ocurre así con sus aventuras de dobles y falsos culpables a la fuga, ni con su énfasis en la fragilidad de la vida intima, de plena actualidad en tiempos de filtraciones e identidades líquidas.

Hechas esas anotaciones en el debe y el haber, el balance arroja un saldo positivo. Confirmando la intuición de Simmel de que las sociedades secretas son una excelente escuela para el estudio de las relaciones sociales, apreciamos que estos thrillers poseen un notable valor didáctico de cara a la enseñanza de los postulados de Simmel y Goffman acerca del papel del secreto en la sociabilidad; además, por supuesto, de documentar el respeto a los arcana imperii de la intelligentsia liberal a la que pertenecía su realizador (para la sociología del cine, todo filme, incluido los de ficción, es un documental). Todo esto sin olvidar el servicio que, al escenificar las paradojas y ambigüedades de los constructos de identidades, las películas prestan a la interpretación de fenómenos propios de una sociedad digital, como identidades falsas, robo de identidades y desajustes entre las identidades online y offline.

\section{BibLiOgRAFÍA}

Alonso, J. (2014). Las transparencias engañan. In M. Albergamo (Ed.), La transparencia engaña (pp. 69-82). Madrid: Biblioteca Nueva.

Boltanski, L. (2012). Énigmes et complots. Une enquête à propos d'enquêtes. Paris: Gallimard.

Bonitzer, P. (2002). Hitchcockian suspense. In S. Zizek (Ed.), Everything you wanted to know about Lacan (but were afraid to ask Hitchcock) (pp. 15-30). London: Verso.

Canetti, E. (1960). Masse und Machte. Hamburg: Classen Verlag.

Corber, R. (1993). In the name of National Security: Hitchcock, Homophobia, and the Political Construction of Gender in Postwar America. Durham: Duke University Press.

Donaldson, P. (1988). Machiavelli and the Mystery of State. Cambridge: Cambridge University Press.

Eco, U. (1992). Los límites de la interpretación. Barcelona: Lumen.

Deflem, M. (2007). Alfred Hitchcock and Sociological Theory: Parsons Goes to the Movies. Sociation Today, 5(1). Disponible en: http://www.ncsociology.org/sociationtoday/v51/mat.html. Última consulta: 30/05/2016. 
Dewerpe, A. (1994). Espion, une anthropologie historique du secret d'Etat contemporain. Paris: Gallimard.

Fabbri, P. (1990) II segreto. Sfera, 13. Disponible en: http://www.paolofabbri.it/articoli/segreto.html. Ültima consulta: 29/03/2016.

Fabbri, P. (2012). Todos somos agentes dobles. Revista de Occidente (372375), 113-133.

Finkenauer, C., Engels, R. \& Meeus, W. (2002). Keeping Secrets from Parents: Advantages and Disadvantages of Secrecy in Adolescence. Journal of Youth and Adolescence, 31(2), 123-136.

Francescutti, P.; Serra, M.; Gómez Pascual, O; y Magallón, R. (2012). El fenómeno Wikileaks: entre la teoría de la información y la comunicacion estratégica. Revista de Occidente, (374-375), 197-211.

Francescutti, P. (2014). El espectáculo de la revelación. Autorreferencialidad periodística en la cobertura del 'Cablegate'. In J. Lozano \& S. Días (Eds.), Vigilados. Wikileaks o las nuevas fronteras de la información (pp. 97-124). Madrid: Biblioteca Nueva.

Goffman, E. (1959). The Presentation of Self in Everyday Life. Edinburgh: University of Edinburgh Social Sciences Research Centre.

Goffman, E. (1963). Stigma: Notes on the Management of Spoiled Identity. New Jersey: Prentice Hall.

Gotlieb, S. (Ed.) (1997). Hitchcock on Hitchcock, Selected Writings and Interviews. Berkeley: University of California press.

Horn, E. (2011). Logics of Political Secrecy. Theory, Culture $\in$ Society, 28(7-8), 103-122.

Koselleck, R. (2007). Crisis y crítica. Un estudio de la patogénesis del mundo burgués. Madrid: Trotta.

Krutnik, F. (2013). Theatre of Thrills: The culture of suspense. New Review of Film and Television Studies, 11(1), 6-33.

Lenoir-Bellec, C. (2004). Fautes et secrets de famille. Les tragédies de l'intime selon Eugène Sue et Emile Zola. In Sémiologie du secret (pp. 59-82). Malissard: Aleph.

Lozano, J. (2014). Secretos de la transparencia. In M. Albergamo (Ed.), La transparencia engaña (pp. 153-164). Madrid: Biblioteca Nueva.

Marimbert, J-J. (1959). Analyse d'une oeuvre: La mort aux trousses. Paris: Vrin.

Marin, L. (2012). Lógicas del secreto. Revista de Occidente, (212-213), 1-26. 
Marx, G. \& Muschert, G. (2008). Simmel on Secrecy. A Legacy and Inheritance for the Sociology of Information. In C. Rol \& Ch. Papilloud (Eds.), Soziologie als Möglichkeit (pp. 217-233). Wiesbaden: Verlag für Sozialwissenschaften.

Metz, Christian (1977). The Imaginary Signifier. Psychoanalysis and the Cinema. Bloomington: Indiana University Press.

Meyrowitz, J. (1985). No sense of Place: The impact of electronic Media on Social Behaviour. New York: Oxford University Press.

Meyrowitz, J. (2013). Nuevas extensiones del aquí y el ahora. Revista de Occidente, (386-387), 151-176.

Nisbet, R. (1990). La formación del pensamiento sociológico l. Buenos Aires: Amorrortu.

Orr, J. (2005). Hitchcock and Twentieth Century Cinema. London: Walflower Press.

Sandis, C. (2009). Hitchcock's Conscious Use of Freud's Unconscious. Europe's Journal of Psychology, (3), 56-81.

Simmel, G. (1906). The sociology of secrecy and of secret societies. The American Journal of Sociology, XI(4), 441-498.

Serra, M. (2014). Entrevista a Alberto Abruzzese. In S. Díaz \& J. Lozano (eds.), Vigilados. Wikileaks o las nuevas fronteras de la información (pp. 279296). Madrid: Biblioteca Nueva.

Thomson, D. (2010). The New Biographical Dictionary of Film. London: Little Brown.

Truffaut, F. (1974). El cine según Hitchcock. Madrid: Alianza.

Wiszniewski, D. \& Coyne, R. (2002). Mask and Identity: The Hermeneutics of Self-Construction in the Information Age. In K. A. Renninger \& W. Shumar (Eds.), Building Virtual Communities. Learning and Change in Cyberspace (pp. 191-214). Cambridge, Cambridge University Press.

\section{Filmografía citada}

Bridges, J. (1979). The China Syndrome. EE UU.

Hitchcock, A. (1935). The 39 steps. Reino Unido.

Hitchcock, A. (1936). Secret Agent. Reino Unido.

Hitchcock, A. (1938). The Lady vanishes, Reino Unido

Hitchcock, A. (1940). Foreign Correspondent. EE UU. 
Hitchcock, A. (1940). Rebecca. EE UU.

Hitchcock, A. (1941). Suspicion. EE UU.

Hitchcock, A. (1942). Saboteur. EE UU.

Hitchcock, A. (1943). Shadow of a Doubt. EE UU.

Hitchcock, A. (1944). Lifeboat. EE UU.

Hitchcock, A. (1945). Spellbound. EE UU.

Hitchcock, A. (1946). Notorious. EE UU.

Hitchcock, A. (1948). The Rope. EE UU.

Hitchcock, A. (1949). Under Capricorn. Reino Unido.

Hitchcock, A. (1950). Stage Fright. Reino Unido.

Hitchcock, A. (1951). Strangers on a Train. EE UU.

Hitchcock, A. (1954). I confess. EE UU.

Hitchcock, A. (1954). Rear Window. EE UU.

Hitchcock, A. (1954). Dial for Murder. EE UU.

Hitchcock, A. (1955). To catch a thief. EE UU.

Hitchcock, A. (1955). The Trouble with Harry. EE UU.

Hitchcock, A. (1956). The man who knew too much. EE UU.

Hitchcock, A. (1956). The Wrong Man. EE UU.

Hitchcock, A. (1958). Vertigo. EE UU.

Hitchcock, A. (1959). North by Northwest. EE UU.

Hitchcock, A. (1960). Psycho. EE UU.

Hitchcock, A. (1963). The Birds. EE UU.

Hitchcock, A. (1964). Marnie. EE UU.

Hitchcock, A. (1966). Torn Curtain. EE UU.

Hitchcock, A. (1966). Topaz. EE UU.

Hitchcock, A. (1972). Frenzy. Reino Unido.

Hitchcock, A. (1976). Family Plot. EE UU.

Mann, M. (1999). The Insider Men. EE UU.

Pakula, A. (1976). All the President's Men. EE UU. 